\title{
CUTTING-OUT OF THE DYNAMIC HIP SCREW RELATED TO ITS POSITION
}

\author{
MARTYN J. PARKER
}

The commonest cause of failure of fixation of extracapsular fractures treated by a dynamic hip screw (DHS) is cutting-out of the screw from the femoral head. Incidences of $5.3 \%$ (Jensen, Tøndevold and Mossing 1978) and $16.8 \%$ (Davis et al 1990) have been reported. This study aims to determine the relationship between the exact position of the screw and subsequent cutting-out.

Patients and methods. The radiographs of a series of such patients were reviewed to determine the position of the screw within the femoral head immediately after operation. The position in 25 patients, in whom the screw later cut out, was compared with the position in 200 cases in which there was radiographic evidence of bony union without cut-out. We defined cutting-out as projection of the screw from the femoral head by more than $1 \mathrm{~mm}$. out. The statistical significance of the difference by the $t$ test was $p<0.001$ (95\% confidence limits 6.7 to 19.2). For the lateral radiograph the average positions were 45 for uneventful union and 36 for cutting-out $(p=0.02$; $95 \%$ confidence limits 2.6 to 16.4 ).

Discussion. Previous studies have used a subjective assessment, dividing the femoral head into superior, central and inferior segments for the AP view and anterior, central and posterior segments for the lateral view. Davis et al (1990) favoured the central position on both views, but Mainds and Newman (1989) and Thomas (1991) considered that a central or inferior position on the AP view was best.

The measurements of the position of the screw allowed statistical evaluation of the results, showing that

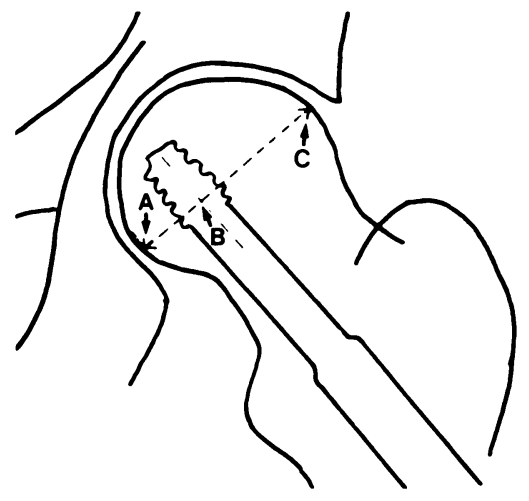

Fig. 1

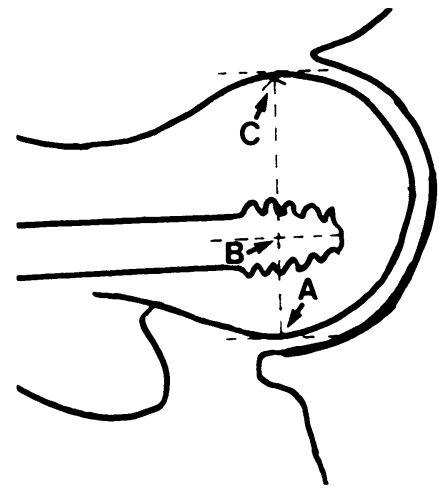

Fig. 2

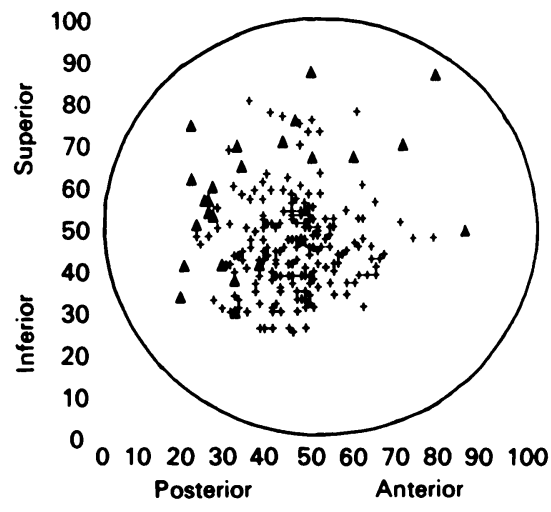

Fig. 3
The position of the screw was determined on anteroposterior (AP) and lateral radiographs by the method shown in Figures 1 and 2, then recording the ratio of $\mathrm{AB}$ to $\mathrm{AC}$, multiplied by 100 , to give a range from 0 to 100 for each view.

Results. The position of each screw within the femoral head is shown diagrammatically in Figure 3, in which a triangle represents a screw which cut out and a cross one that did not.

On the AP radiograph the average position of the screw was at 45 for uneventful union and 58 for cutting-

M. J. Parker, FRCS, Orthopaedic Research Registrar Peterborough District Hospital, Thorpe Road, Peterborough PE36DA, England.

(C) 1992 British Editorial Society of Bone and Joint Surgery $0301-620 X / 92 / 4 R 45 \$ 2.00$

J Bone Joint Surg [Br] 1992; 74-B:625. cutting-out was more frequent when screws were placed superiorly or posteriorly. The aim should be to place the screw centrally or inferiorly on the AP view and centrally on the lateral view.

No benefits in any form have been received or will be received from a commercial party related directly or indirectly to the subject of this article.

\section{REFERENCES}

Davis TRC, Sher JL, Horsman A, et al. Intertrochanteric femoral fractures: mechanical failure after internal fixation. $J$ Bone Joint Surg [Br] 1990; 72-B:26-31.

Jensen JS, Tendevold E, Mossing N. Unstable trochanteric fractures treated with the sliding-plate system: a biomechanical study of unstable trochanteric fractures III. Acta Orthop Scand 1978; 49:392-7.

Mainds CC, Newman RJ. Implant failures in patients with proximal fractures of the femur treated with a sliding screw device. Injury $1989 ; 20: 98-100$.

Thomas AP. Dynamic hip screws that fail. Injury $1991 ; 22: 45-6$. 